ASIMETRIS: JURNAL PENDIDIKAN MATEMATIKA DAN SAINS

$$
\text { p-ISSN } 2721 \text { - 8724, e-ISSN } 2722 \text { - } 0214
$$

Website Jurnal: http://journal.umuslim.ac.id/index.php/asm/

\begin{aligned} & Info Artikel: Direvisi pada 16 Oktober 2021 \\ & Disubmit pada 11 Oktober 2021 Diterima pada 20 Oktober 2021 \\ & Direview pada 15 Oktober 2021 Tersedia secara daring pada 28 Oktober 2021 \\ & \hline\end{aligned}

\title{
PENERAPAN MODEL PEMBELAJARAN PROBLEM BASED LEARNING BERBANTUAN ALAT PERAGA PAPAN STATISTIKA UNTUK MENINGKATKAN KEMAMPUAN KOMUNIKASI MATEMATIS SISWA
}

\author{
Aulia Safitri' ${ }^{1}$ Rahmi Wahyuni², Husnidar ${ }^{3}$ \\ 1,2,3 Pendidikan Matematika Universitas Almuslim Bireuen, Aceh, Indonesia \\ Alamat email: auliasafitri05051999@gmail.com
}

\begin{abstract}
ABSTRAK. Penelitian ini bertujuan untuk mengetahui peningkatan kemampuan komunikasi sistematis siswa melalui model pembelajaran Problem Based Learning dengan berbantuan alat peraga papan statistik pada materi pemusatan data/statistik di kelas VIII/1 SMP Negeri 2 Jangka. Penelitian ini menerapkan pendekatan kualitatif dengan jenis penelitian tindakan kelas, subjek penelitian adalah siswa kelas VIII/1 SMP Negeri 2 Jangka yang berjumlah 21 orang siswa. Adapun instrument yang digunakan adalah 4 soal tes kemampuan komunikasi matematis siswa. Dari hasil tes akhir sikus I, Skor presentase yang diperoleh belum sesuai dengan kriteria hasil yang ditetapkan pada siklus yaitu hanya $66,6 \%$ yang mendapatkan nilai $\geq 65$ sedangkan hasil observasi terhadap kegiatan peneliti dan siswa sudah mencapai target yaitu 73,3\% dan 73,3\%, untuk itu peneliti masuk ke siklus II. Pada siklus II berdasarkan hasil tes akhir mencapai 85,7\% yang mendapat nilai $\geq 65$ dan hasil observasi terhadap kegiatan peneliti dan siswa sudah mencapai kriteria yang ditetapkan yaitu sebanyak $88,8 \%$ dan $86,6 \%$. Jadi berdasarkan hasil penelitian yang diperoleh dari analisis data menunjukkan bahwa pembelajaran dengan menggunakan model pembelajaran Problem Based Learning (PBL) dengan berbantuan alat peraga papan statistik dapat meningkatkan kemampuan komunikasi matematis siswa.
\end{abstract}

Kata Kunci: Komunikasi Matematis Siswa, Problem Based Learning

ABSTRAK. This study aims to determine the improvement of students' systematic communication skills through the Problem Based Learning learning model with the aid of the statistical board teaching aids on data/statistics concentration material in class VIII/1 of SMP Negeri 2 Jangka. This study uses an approach with the type of classroom action research, the research subjects are students of class VIII/1 SMP Negeri 2Term which collects 21 students. The instruments used were 4 test questions of students' mathematical communication skills. The percentage score obtained from the results of the final test of the first cycle is not in accordance with the results criteria set in the cycle, namely only $66.6 \%$ who get a value, while the results of observations of activities and researchers have reached the target of $73.3 \%$ and $73.3 \%$, respectively. For this reason, the researcher entered cycle II. In the second cycle, based on the results of the final test, it reached $85.7 \%$, which scored and the results of observations on the activities of researchers and students had reached the specified criteria, namely $88.8 \%$ and $86.6 \%$, respectively. So based on the research results obtained from data analysis, it shows that learning by using the Problem Based Learning (PBL) learning model with the help of statistical aids can improve students' mathematical communication skills.

Keyword: Student Mathematical Comunication, Problem Based Learning

\section{PENDAHULUAN}

Pendidikan merupakan suatu bentuk usaha yang terencana untuk mewujudkan suasana belajar dan proses pembelajaran agar peserta didik secara dapat mengembangkan secara aktif potensi dirinya untuk memiliki kekuatan spiritual keagamaan, kepribadian, pengendalian diri, bangsa, dan negara.

Pendidikan dapat meningkatkan sumber daya manusia, karena dengan adanya pendidikan dapat, meningkatkan keterampilan, pengetahuan dan menanamkan nilai-nilai karakter dengan 
baik. Menurut (Novianti \& Khaulah, 2021) " Pemahaman siswa yang rendah dalam menghubungkan konsep matematika dengan topok lain dapat disebabkan karena pembelajaran selama ini luring aktif dan masih menggunakan model pembelajaran konvensional."

Kemampuan komunikasi matematika dalam pembelajaran matematika sangat diperlukan karena dapat mengorganisasikan berpikir matematis siswa baik secara lisan maupun tulisan. Siswa mempunyai kemampuan komunikasi akan membiasakan siswa tersebut pada pemahaman matematika tentang konsep matematika yang akan dipelajari. Kemampuan yang harus dimiliki siswa dalam pembelajaran matematika adalah kemampuan komunikasi matematis yang merupakan suatu proses yang digunakan untuk menyelesaikan permasalahan dengan membuat langkah-langkah dan ide-ide yang dihubungkan dalam kehidupan nyata. Supaya siswa dapat memecahkan permasalahan yang ada, maka siswa juga harus memiliki kemampuan komunikasi yang tinggi. Dengan kemampuan komunikasi yang tinggi maka siswa dapat dengan mudah menyelesaikan masalahmasalah yang ada dalam kehidupan nyata siswa,yang berkaitan dengan kemampuan komunikasi matematis.

Kemampuan komunikasi matematis siswa merupakan kemampuan siswa dalam menyalrka ide matematika dalam proses pembelajaran secara lisan maupun tulisan. Melalui komunikasi ini, seluruh anggota yang berada di dalam kelas akan saling mengkomunikasikan segala sesuatu yang terkait dengan pembelajaran. akan ada interaksi guru dengan siswanya maupun siswa dengan siswa lainnya. Menurut (Prayitno et al., 2013) Komunikasi matematis adalah salah satu alternative yang harus diambil siswa untuk menyatakan dan menafsirkan gagasan- gagasan matematika secara lisan maupun tertulis, baik dalam bentuk gambar, tabel, diagram, rumus, ataupun demonstrasi.

Menurut (Gunantara et al., 2014) Problem Based Learning (PBL) merupakan suatu model pembelajaran yang memmbuat siswa terlibat langsung dalam memecahkan masalah nyata. Model ini menyebabkan motivasi dan rasa ingin tahu menjadi meningkat.

Model pembelajaran PBL dengan alat peraga papan statistika merupakan suatu model pembelajaran yang disajikan masalah secara sistematis yang berkaitan dengan kehidupan nyata, lalu siswa diarahkan untuk dapat menyusun alternative penyelesaian masalah, sehingga siswa dapat mengembangkan pengetahuan sendiri dan keterampilan berpikir tingkat lebih tinggi, mengembangkan rasa percaya diri da kemandirian dan dikaitkan dengan alat peraga papan statistika, sehingga tujuan akhir yag didapat siswa adalah pemahaman mengenai apa yang sudah dipelajari. pada cara penyajian materi pembelajaran, media pembelajaran dan metode mengajar yang digunakan oleh guru pada proses belajar mengajar menjadi salah satu keberhasilan siswa dalam belajar

\section{Langkah-langkah Model Problem Based Learning (PBL)}

Terdapat dua tingkatan dalam pembelajaran PBL yaitu yang pertama adalah siswa harus menyelesaikan satu masalah spesifik dan memahami materi yang saling berhubungan. Kedua, siswa wajib mengembangkan pemecahan masalah dan menjadi siswa yang terklatih dan mandiri. Langkah pembelajaran untuk PBL terjadi dalam empat fase (Nafiah \& Suyanto, 2014) Fase - fase tersebut yaitu sebagai berikut.

\begin{tabular}{c} 
Tabel 2.1 $\begin{array}{c}\text { Fase - fase Penerapan Model } \\
\text { Pembelajaran Problem Based } \\
\text { Learning }\end{array}$ \\
\hline
\end{tabular}

Fase dalam PBL Perilaku Guru

Fase 1:

Memberikan

arahan tentang

permasalahanya

pada siswa

$$
\begin{aligned}
& \text { Guru membahas tujuan } \\
& \text { pembelajaran, } \\
& \text { menceritakan berbagai } \\
& \text { kebutuhan penting, dan } \\
& \text { memotivasi siswa untuk } \\
& \text { aktif terlibat dalam } \\
& \text { kegiatan pemecahan }
\end{aligned}
$$


masalah

\begin{tabular}{ll}
\hline Fase 2: & Guru membantu siswa \\
Menmberikan & untuk mendefinisikan dan \\
arahan siswa & memfasilitasi tugas \\
untuk meneliti & belajar yang \\
& berhubungan dengan \\
& permasalahannya
\end{tabular}

\begin{tabular}{ll}
\hline Fase 3: & Guru membantu siswa \\
Membantu & untuk mendapatkan \\
investigasi mandiri & informasi yang akurat, \\
dan berkelompok & $\begin{array}{l}\text { melakukan eksperimen, } \\
\text { dan mencari solusi }\end{array}$
\end{tabular}

\begin{tabular}{ll}
\hline $\begin{array}{l}\text { Fase 4: } \\
\begin{array}{l}\text { Mengembangkan } \\
\text { dan } \\
\text { mempresentasikan } \\
\text { laporan }\end{array}\end{array}$ & $\begin{array}{l}\text { Guru membantu siswa } \\
\text { dalam merencanakan dan } \\
\text { menyiapkan laporan yang } \\
\text { tepat }\end{array}$ \\
\hline $\begin{array}{l}\text { Fase 4: } \\
\text { Menganalisis dan } \\
\text { mengevaluasi hasil } \\
\text { akhir }\end{array}$ & $\begin{array}{l}\text { Guru melakukan evaluasi } \\
\text { terhadap paparan siswa } \\
\text { danelakukan refleksi } \\
\text { terhadap penyelidikannya } \\
\text { dan proses-proses yang } \\
\text { digunakan }\end{array}$ \\
\hline
\end{tabular}

\section{METODE PENELITIAN}

Jenis penelitian yang digunakan dalam penelitian ini adalah penelitian tindakan kelas. Menurut (Arikunto, 2012) Penelitian tindakan kelas dari salah satu tempat melaksanakan penelitian menunjukkan isi yang terkandung di dalamnya yaitu sebuah penelitian yang dilakukan di kelas. Ada tiga kata yang membentuk pengertian dari PTK yaitu sebagai berikut:

1. Penelitian ini menunjukkan pada suatu hal dengan mencermati suatu objek dengan menggunakan cara dan aturan metodologi tertentu untuk memperoleh data atau informasi yang bermanfaat dalam meningkatkan kualitas suatu hal penting bagi peneliti.
2. Tindakan pada sesuatu kegiatan yang dilakukan dengan tujuan tertentu.

3. Kelas dalam hal ini tidak teorikan dalam pengertian ruang kelas, tetapi dalam pengertian yang lebih spesifik.

Berdasarkan pendapat tersebut dapat dipahami bahwa penelitian tindakan kelas adalah kegiatan penelitian dengan mengkondisikan sebuah kegiatan belajar yang diberikan suatu tindakan pembelajaran dalam sebuah kelas, sehingga bertujuan dapat menyelesaikan masalah atau meningkatkan kualitas pembelajaran di kelas tersebut. Tindakan yang secara sengaja dimunculkan tersebut di berikan oleh guru atau peneliti yang memahami hakikat penelitian tindakan kelas.

Lebih lanjut, Arikunto (Arikunto et al., 2006) menegaskan bahwa pengertian kelas tidak diharuskan penelitian tersebut dilakukan pada ruang kelas, akan tetapi dalam diartikan yang lebih spesifik, yaitu kelas adalah sekelompok siswa yang dalam waktu yang sama, menerima pelajaran yang sama dari guru yang sama juga dan tempatnya bisa diluar ruangan. Proses dasar pelaksanaan penelitian tindakan kelas mengacu pada siklus spiral yang terdiri dari 4 komponen yaitu: (1) perencanaan, (2) pelaksanaan, (3) pengamatan, (4) refleksi.

Diagram pelaksanaan PTK menurut (Arikunto et al., 2006) dapat pada gambar 3.1 berikut ini:

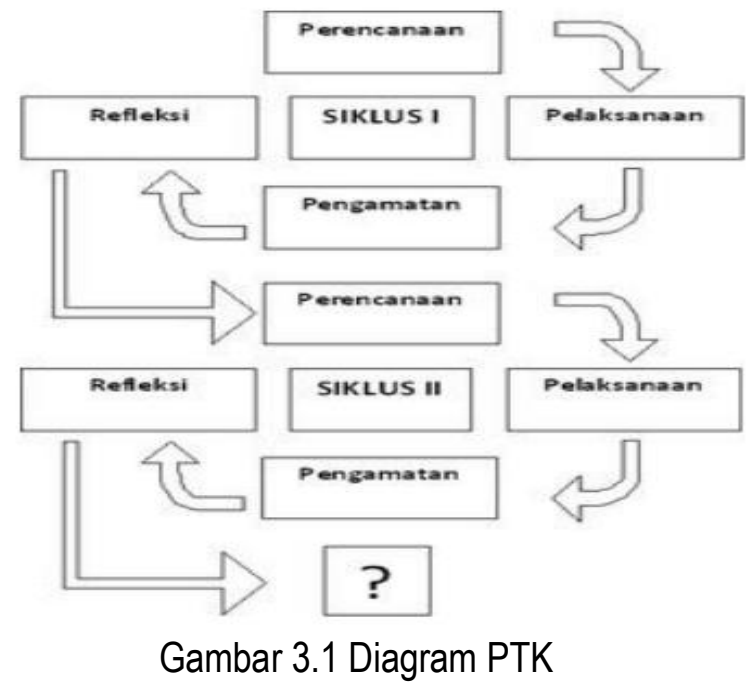


Adapun metode analisis untuk masingmasing data dalam penelitian ini adalah sebagai berikut:

a. Analisis Tes Hasil Belajar Siswa

Adapun data hasil belajar siswa diperoleh melalui tes. Hasil tes dicari dengan menghitung daya serap untuk masing-masing siklus. Dengan demikian rumus yang digunakan adalah sebagai berikut:

Ketuntasan belajar $=\frac{\text { jumlah soal yang tuntas }}{\text { jumlah seluruh soal }} \times 100 \%$

b. Analisis observasi guru dan siswa

Penentuan persentase keberhasilan tindakan didasari pada data skor yang diperoleh dari hasil observasi, aktivitas guru dan peserta didik peneliti menggunakan rumus persentase sebagai berikut: (Tarigan \& Susanti, 2013):

Persentase nilai rata-rata $=\frac{\text { jumlah skor }}{\text { skor maksimal }} \times 100 \%$

\section{Keterangan :}

Jumlah skor : Jumlah skor yang diberikan pengamat dari tahap awal hingga tahap akhir

Skor maksimal : Jumlah semua indikator tiap tindakan $\mathrm{x}$ skor tertinggi

Sedangkan untuk menentukan skor presentase rata - rata pada setiap tindakan terhadap kegiatan peneliti dengan menggunakan rumus sebagai berikut:

$$
\mathrm{SPP}=\frac{S P_{1}+S P_{2}}{2} \ldots \ldots .(2)
$$

SPP : Skor Presentase rata-rata kegiatan peneliti

$S P_{1} \quad:$ Skor Presentase pengamat I

$S P_{2} \quad$ : Skor Presentase pengamat II

Adapun kriteria keberhasilan aktivitas guru dan siswa dalam pelaksanaan pembelajaran (Siswono, 2008) sebagai berikut:

$$
\begin{array}{ll}
90 \% \leq \mathrm{SP} \leq 100 \% & : \text { Sangat Baik } \\
80 \% \leq \mathrm{SP} \leq 90 \% & : \text { Baik } \\
70 \% \leq \mathrm{SP} \leq 80 \% & : \text { Cukup }
\end{array}
$$

$$
\begin{array}{ll}
60 \% \leq \mathrm{SP} \leq 70 \% & : \text { Kurang } \\
0 \%<\mathrm{SP} \leq 60 \% & : \text { Sangat Kurang }
\end{array}
$$

Penelitian ini akan dilaksanakan dalam dua siklus, masing-masing siklus terdiri dari dua kali pertemuan. Tahap-tahap pelaksanaan Penelitian Tindakan Kelas (PTK) sebagaimana yang disampaikan oleh (Arikunto, 2012) yaitu terdiri dari plan (rencana), act(tindakan), observe (observasi), dan reflect (perenungan).

\section{HASIL PENELITIAN DAN PEMBAHASAN}

Tes awal disajikan dalam beberapa soal terdiri dari 4 soal dan alokasi waktu 40 menit yang diikuti oleh 21 orang siswa di kelas tersebut. Pada saat tes awal berlangsung peneliti memberikan pengawasan yang ketat agar kemurnian hasil tes terjamin. Tes yang telah dikerjakan oleh siswa kemudian dikoreksi oleh peneliti.

Berdasarkan tes awal yang dilakukan pada hari Selasa tanggal 16 Maret 2021, jumlah siswa yang memperoleh skor $\geq 65$ adalah 8 orang siswa, sehingga skor presentasenya yaitu :

jumlah siswa yang memperoleh skor $\geq 65$
jumlah siswa yang ikut tes
Berdasarkan nilai tes akhir siklus । diperoleh data bahwa, siswa yang mendapatkan skor $\geq 65$ sebanyak 14 siswa, yang mendapatkan skor $<65$ sebanyak 7 siswa. Data yang didapatkan tersebut dihitung persentase dengan menggunakan rumus yaitu :

$\frac{\text { jumlah siswa yang memperoleh skor } \geq 65}{\text { jumlah siswa yang ikut tes }} \times 100 \%=\frac{14}{21} \times 100 \%=66,6 \%$

Dengan demikian, sesuai dengan kriteria yang sudah ditetapkan, yaitu jika $\geq 85 \%$ siswa mendapatkan $\geq 65$ maka pelaksanaan siklus I dengan hasil tes belum berhasil. Berdasarkan data yang diperoleh dari hasil tes ini, belum memenuhi standar keberhasilan dari segi hasil karena belum memenuhi kriteria ketuntasan, maka peneliti perlu melakukan siklus II. 
Pada kegiatan observasi yang dilakukan pada siklus I dilakukan oleh guru mata pelajaran matematika dan teman sejawat, untuk mengetahui kesesuaian antara rencana pembelajaran dengan pelaksanaannya di kelas. Data hasil observasi menunjukkan bahwa peneliti melakukan kegiatan pembelajaran sesuai dengan rencana pembelajaran yang telah disusun sebelumnya.

Observasi dilakukan setiap pertemuan, untuk penentuan nilai presentase pada pertemuan dari masing - masing pengamat terhadap kegiatan peneliti dan skor presentase aktivitas siswa yang diamati oleh teman sejawat.

Hasil observasi terhadap aktivitas guru pada siklus I yaitu diperoleh presentase dari pengamat I sebanyak $75,5 \%$, dan dari pengamat II sebanyak $71,1 \%$. Presentase rata - rata pada setiap kegiatan peneliti yaitu sebanyak $73,3 \%$. Hasil observasi terhadap kegiatan siswa pada siklus I diperoleh presentase dari pengamat I sebanyak $71,1 \%$, dan dari pengamat II sebanyak $75,5 \%$. Sedangkan presentase rata - rata pada setiap kegiatan peneliti yaitu sebanyak $73,3 \%$. Berdasarkan skor presentase rata - rata di atas, dapat disimpulkan bahwa taraf keberhasilan aktivitas siswa pada siklus I berdasarkan observasi 2 orang pengamat termasuk dalam kategori cukup.

Pada siklus II, skor persentase keberhasilan hasil tes akhir tindakan nilai siswa tersebut mencapai $85,7 \%$, dimana terjadi peningkatan dari $19,1 \%$ dari $66,6 \%$. Oleh karena itu perolehan nilai tesrsebut sesuai criteria yang ditetapkan pada tindakan, jika $\geq 85$ siswa mendapatkan $\geq 65$ maka pelaksanaan siklus II sudah berhasil dan tuntas sehingga penelitian berhenti pada siklus ke II sehingga tidak dilanjutkan lagi pada siklus selanjutnya

Berdasarkan hasil wawancara terhadap subjek wawancara yang diperoleh keterangan bahwa siswa senang belajar dengan menggunakan model pembelajaran Problem Based Learning. Hasil observasi dua pengamat pada siklus II mengalami peningkatan. Kegiatan peneliti mendapatkan skor presentase rata - rata
$88,8 \%$. Kegiatan siswa pada siklus II mendapatkan skor presentase rata - rata 86,6\%.

Analisis data menunjukkan bahwa model pembelajaran Problem Based Learning dengan berbantuan alat peraga Papan statistik yang telah dilaksanakan di kelas VIII/1, SMP Negeri 2 Jangka tahun pelajaran 2020-2021 dapat meningkatkan kemampuan komunikasi matematis siswa pada materi Pemusatan data/Statistik. Dari pembahasan diatas menunjukkan bahwa indicator kemampuan komunikasi matematis siswa tercapai dengan menggunakan model pembelajaran Problem Based Learning di kelas VIII/1 SMP Negeri 2 Jangka.

\section{SIMPULAN}

berikut:

Simpulan yang diambil adalah sebagai

1. Hasil belajar siswa mengalami peningkatan dari siklus I 66,6 meningkat pada siklus ke II menjadi $85,7 \%$

2. Hasil observasi aktivitas siswa juga mengalami peningkatan dari siklus I ke siklus II.

\section{DAFTAR PUSTAKA}

Arikunto, S. (2012). Prosedur Penelitian Suatu Pendekatan Praktek.

Arikunto, S., Suhardjono, \& Supardi. (2006). Penelitian Tindakan Kelas.

Gunantara, Suarjana, \& Riastini, N. (2014). Penerapan Model Pembelajaran Problem Based Learning Untuk Meningkatkan Kemampuan Pemecahan Masalah Matematika Siswa Kelas V. Jurnal Mimbar PGSD Universitas Pendidikan Ganesha, 2(1).

Nafiah, Y. N., \& Suyanto, W. (2014). PENERAPAN MODEL PROBLEM-BASED LEARNING UNTUK MENINGKATKAN KETERAMPILAN BERPIKIR KRITIS DAN HASIL BELAJAR SISWA THE 
APPLICATION OF THE PROBLEM-BASED LEARNING MODEL TO IMPROVE THE STUDENTS CRITICAL THINKING SKILLS AND LEARNING OUTCOMES. Jurnal Pendidikan Vokasi, 4(1).

Novianti, N., \& Khaulah, S. (2021). PENERAPAN MODEL PEMBELAJARAN MIND MAPPING TERHADAP PENINGKATAN KEMAMPUAN KONEKSI MATEMATIS SISWA PADA MATERI PROGRAM LINEAR DI KELAS XI MAN PEUSANGAN. Jurnal Variasi, 13(Nomor 1), 26-29. https://doi.org/https://doi.org/10.51179/vrs.v $13 \mathrm{i} 1.502$

Prayitno, S., Suwarsono, S., \& Siswono, T. (2013). Indentifikasi Indikator Kemampuan Komunikasi Matematis Siswa dalam Menyelesaikan Soal Matematika Berjenjang Pada Tiap-tiap jenjangya. Prosiding Konferensi Nasional Pendidikan Matematika $\quad V, \quad V$. file:///C:/Users/JAGAT/Downloads/INDENTI FIKASI INDIKATOR KEMAMPUAN KOMUNIKASI MATEMATIS SISWA DALAM MENYELESAIKAN SOAL MATEMATIKA BERJENJANG PADA TIAPTIAP JENJANGNYA.pdf

Tarigan, M., \& Susanti, P. (2013). Pengaruh Kompetensi, Etika, dan Fee Audit terhadap Kualitas Audit. Jurnal Akuntansi, 13(No. 1 April 2013), 803-832. http://ejournal.ukrida.ac.id/ojs/index.php/ak un/article/view/819/798 